\title{
Prevalence of Porcine Circovirus Type 2 (PCV-2) in Smallholder Pig Farms in Thung-Yai, Nakhon Si Thammarat, Thailand
}

\author{
Vassakorn KHOPHLOIKLANG ${ }^{1, \#}$, Ladawan SARIYA ${ }^{2}$, \\ Pornsak NARA-ARJ ${ }^{3}$, Manta POOMIKASEMSAK ${ }^{1}$, \\ Kosit AREEKIT ${ }^{1}$, Nilobol KAMYUN ${ }^{4}$, Suttida SANGPOOM ${ }^{5}$, \\ Aekkapot CHAMKASEM ${ }^{1,6, \#}$ and Dusit LAOHASINNARONG ${ }^{7, *}$
}

${ }^{I}$ Faculty of Veterinary Science, Rajamangala University of Technology Srivijaya, Nakhon Si Thammarat 80240, Thailand

${ }^{2}$ The Monitoring and Surveillance Center for Zoonotic Diseases in Wildlife and Exotic Animals, Faculty of Veterinary Science, Mahidol University, Nakhonpathom 73170, Thailand

${ }^{3}$ Nakhon Si Thammarat Provincial Livestock Office (Thung Yai), Department of Livestock Development, Nakhon Si Thammarat 80000, Thailand

${ }^{4}$ Department of Mathematics, School of Science, University of Phayao, Phayao 56000, Thailand

${ }^{5}$ Division of Mathematics and Statistics, School of Science, Walailak University,

Nakhon Si Thammarat 80160, Thailand

${ }^{6}$ Akkhraratchakumari Veterinary College, Walailak University, Nakhon Si Thammarat 80160, Thailand

${ }^{7}$ Department of Clinical Sciences and Public Health, Faculty of Veterinary Science, Mahidol University, Nakhonpathom 73170, Thailand

('Corresponding author's e-mail: dusit.lao@mahidol.ac.th)

Received: 6 March 2019, Revised: 14 October 2020, Accepted: 22 November 2019

\begin{abstract}
Porcine circovirus type 2 (PCV2), which is a member of the Circovirus genus in the family of Circoviridae, is a small non-enveloped, closed-circular ssDNA. The PCV2-associated disease is one of the most important infectious agents on pig productivity worldwide, including China, India, Malaysia, and Thailand. It caused 2 major syndromes; postweaning multisystemic wasting syndrome (PMWS) and porcine dermatitis and nephropathy syndrome (PDNS). In addition, PCV2 may cause complexity with a pathogenic agent into porcine circovirus associated diseases (PCVADs). This study aimed to determine the prevalence of PCV2 in smallholder farms in Thung Yai district, Nakhon Si Thammarat, Thailand. A cross-sectional study was performed; 100 blood samples were collected from 13 smallholder pig farms. The samples were classified into 4 groups based on the pig's age; gilts, 6 sows, nursery-to-starter, and from growing to finishing pigs. Blood samples were carried out for DNA +extraction and nested-PCR. The epidemiological study showed $9 \%$ positive by genetic detection.

The result suggested that growing-to-finishing pigs had significant PCV2 infection, followed by nursery-to-starter pigs and sow groups. In addition, multiple farms showed a high positive and significant correlation $(\mathrm{Cr} \approx 0.245)$. These results reveal a low prevalence of PCV2 in endemic regions in southern Thailand, which may help in the local control evaluation and eradication programs. Furthermore, the phylogenic study of local strain should be investigated for the occurrence of PCV2 genetic evolution in Thailand and neighboring countries.
\end{abstract}

Keywords: Porcine circovirus type 2, PCV2, Nakhon Si Thammarat, PCR, ORF2, Capsid

\footnotetext{
${ }^{\#}$ Equal contribution
} 


\section{Introduction}

Circovirus is the smallest virus in Circovirus genus members in the family of Circoviridae, a small non-enveloped, closed-circular ssDNA genome of approximately $1.7 \mathrm{~kb}$ in length. The genomic material consists of 3 major open reading frames; (ORFs); ORF1 (Rep), ORF2 (Cap), and ORF3 (Protein associated with apoptosis) [1-4]. Circoviruses were mainly from avian species. Great members of the family Circoviridae have a wide host range in fish, insects, and mammals [5-8]. From the previous report, 2 types of circovirus were isolated from the domestic pig. Porcine circovirus 1 (PCV1) was first isolated in cell culture contamination and considered as non-pathogenic [9-11]. On the contrary, PCV2 has been associated with several clinical signs in domestic pigs and caused economic loss directly as Post Weaning Multisystemic Wasting Syndrome (PMWS) and Porcine Dermatitis and Nephropathy Syndrome (PDNS) $[7,12,13]$.

In addition, PCV2-associated diseases have shown genetic diversity; the nucleotide sequence identity between the PCV1 and PCV2 is approximately $86 \%$ in the replication gene and $66.4 \%$ in the capsid gene $[7,14,15]$. The PCV2-associated disease is one of the most important infectious agents on pig productivity worldwide, including China, India, Malaysia, and Thailand. PCV2 leads to a morbidity range from $4-30 \%$, occasionally $50-60 \%$, and mortality ranges from $4-20 \%$. PMWS-associated PCV has a high economic impact on productivity, causing chronic wasting syndromes at 5 - 12 weeks of age with clinical signs, such as growth retardation, weight loss, dyspnea, and anemia jaundice, and lymph nodes enlargement. The pathological lesions have shown granulomatous interstitial pneumonia, lymphadenopathy, multifocal lymphoplasmacytic hepatitis, lymphohistiocytic interstitial nephritis, and pancreatitis. However, the virulent of PMWS-outbreak depend on the herd's immunity and vaccination programs [2,5,16-21]. In contrast, PDNS-associated PCV was first reported in 1990 and has been affected in grower and finishing pigs. The infected pig demonstrated the typical lesion on the skin as multifocal red-purple blotches/scabs and petechial hemorrhage with renal enlargement on gross. The microscopic lesion was marked the necrotizing vasculitis (skin, kidney, mesentery, and spleen), fibrinonecrotizing glomerulitis with nonpurulent interstitial nephritis, and lymphoid-depletion. In addition, PCV2 plays a significant role in complex disease. It is called Porcine Circovirus Associated Diseases (PCVADs) as it undergoes a process of co-infection with bacteria (e.g., Haemophilus parasuis, Streptococcus suis, Mycoplasma hyopneumoniae) and virus (e.g., Swine influenza virus, Porcine Reproductive and Respiratory Syndrome virus). This co-infection leads to high clinical signs and farm production problems [5,8,21-24].

A field study of PCV2 was performed in some countries of North America, Europe, and Asia. Mukherjee et al. [25] reported the prevalence of PCV2 in India's North-Eastern region, approximately $62.25 \%$ in blood samples and $18.94 \%$ in tissue via PCR detection. This suggested that the rural area without vaccination have a high prevalence with PCV2 positive, whereas the prevalence was decreased dramatically with vaccination. Moreover, PCV2a DNA was only detected in non-vaccinated pigs [25-28]. PCV2 was detected the viral shedding in boar semen showing $18.2 \%$ but no difference with antibody detection. Borkenhagen study (2018) demonstrated PCV2 was detected in oral secretion proximately $87.8 \%$ and $23.1 \%$ in farm bioaerosol samples. These studies suggested the PCV2 can be a recurrence in the farm environment [30,31]. In Thailand, PCV2 has been reported since 1993; and PWMS in 1998 PCV2 has been spread widely in the Central and Eastern part of Thailand with high pig population density during 2009 - 2015. The results showed a high positive about $44.09 \%(\mathrm{n}=306 / 694)$ from $80 \%$ $(56 / 70)$ in farms. However, Jantafong (2018) reported that the prevalence of PCV2 infection in Thailand's central region was approximately $10 \%$. Furthermore, PCV2 detection was not significantly different between blood and fecal sample; however, it was related to age-dependent clearly [2,3,28,30-33].

Although Nakhon Si Thammarat province has the highest number of farms in the southern part and the rank of $14^{\text {th }}$ in production in Thailand, the problem becomes more complicated by limited information on PCV2 prevalence and suitable control strategies. This indicates that the investigation of PCV2 prevalence in the southern part is essential to optimize control for smallholder pig farms. Therefore, this project investigates the prevalence of PCV2 in a smallholder pig farm in Southern Thailand, which would 
http://wjst.wu.ac.th

help understand the epidemiology and improve the effective biosecurity system in smallholders and farms in tropical zone conditions.

\section{Materials and methods}

\section{Sample collection}

A total of 100 blood samples with ethylenediamine-tetra-acetic (EDTA) via marginal ear veins of pigs for adult pigs and jugular vein for nursery pigs from 14 smallholder pig farms in Thung Yai district, Nakhon Si Thammarat Province, Thailand (Figure 1) was used in the study. The samples were divided into 4 groups based on the pigs' age, gilt, sow, nursery to starter, and grower to finisher. All blood samples were stored at $4{ }^{\circ} \mathrm{C}$ during transportation and $-80{ }^{\circ} \mathrm{C}$ for subsequent analysis of DNA extraction and polymerase chain reaction (PCR) for PCV2-specific nucleic acids. This experimentation was performed in accordance with DR256126012010. The permission of animal care and use protocol was conducted under RMUTSV IAC-03-13-61.

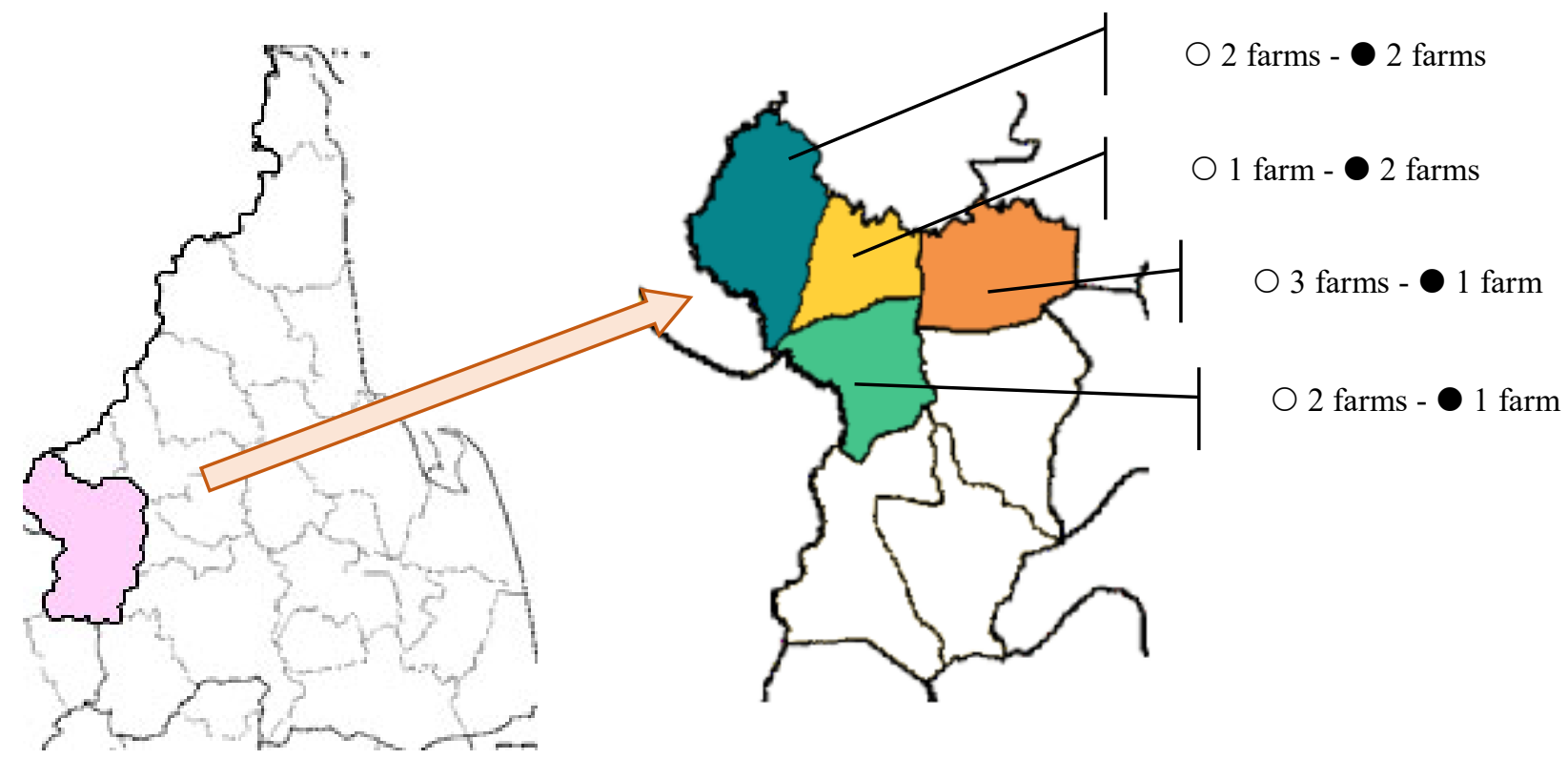

Figure 1 (A) Nakhon Si Thammarat province is in the white area, whereas Thung Yai district is in the shadow area. (B) Thung Yai district map (thick borderline). One hundred samples were collected from 14 farms in 4 sub-districts in Thung Yai district; 4 farms in Bang Rub, 3 farms in Thung Sang, 4 farms in Thung Yai, and 3 farms in Tha Yang sub-districts. All pig farms were divided by production type as 8 breeding farms $(\bigcirc)$ and 6 finishing farms $(\mathbf{O})$.

\section{DNA extraction and one-tube semi-nested PCR}

DNA was extracted from $300 \mu \mathrm{L}$ of blood using a commercial DNA isolation kit (Geneaid Biotech Ltd., Taiwan) by following the manufacturer's instructions. DNA samples were kept in $-20{ }^{\circ} \mathrm{C}$ until used for PCR assays. One-tube semi-nested PCR was selected to amplify 226 bp of PCV2 ORF2 fragment by published primers $[22,29]$. The external primers are PCV-ORF2-290F (5'-TAG GTT AGG GCT GTG GCC TT-3') and PCV- ORF2-535R (5'- CCG CAC CTT CGG ATA TAC TG -3'). The inner primers are PCV-ORF2-290F and PCV-ORF2-516R (5'-ACT GTC AAR CGA ACC ACA GTC A-3'). The DNA sample was resuspended in $100 \mu \mathrm{L}$ of DNA hydration buffer. One-tube semi-nested PCR was carried out in $25 \mu \mathrm{L}$ of total reaction mixture that consisted of $1.25 \mathrm{U}$ i-Taq DNA Polymerase (iNtRON 
http://wjst.wu.ac.th

Biotechnology, Inc., Korea), $2.5 \mu \mathrm{L}$ of 10× PCR buffer (100 mM Tris-HCl (pH 8.3), $500 \mathrm{mM} \mathrm{KCl,} 20$ $\mathrm{mM} \mathrm{MgCl} 2$, and enhancer solution), $2.5 \mu \mathrm{L}$ of $10 \mathrm{mM}$ each dNTP mix, $0.1 \mu \mathrm{L}$ of each primer, $5 \mu \mathrm{L}$ of template DNA, and nuclease-free water. One-tube semi-nested PCR was performed by standard thermal cycler (SimpliAmp ${ }^{\circledR}$, Applied Biosystems) for 2 steps. First step, the conditions were initialized at $94{ }^{\circ} \mathrm{C}$ for $2 \mathrm{~min}$, followed by 30 cycles at $95{ }^{\circ} \mathrm{C}$ for $15 \mathrm{~s}, 58{ }^{\circ} \mathrm{C}$ for $15 \mathrm{~s}$, and $72{ }^{\circ} \mathrm{C}$ for $30 \mathrm{~s}$, and final extension at $72{ }^{\circ} \mathrm{C}$ for $7 \mathrm{~min}$. In the second step, the conditions were carried out as the first step at only 10 cycles, followed by changing annealing temperature to $60{ }^{\circ} \mathrm{C}$ for 25 cycles. The PCR products were electrophoresed in $2 \%$ agarose gel and stained with GelRed ${ }^{\circledR}$ Nucleic Acid Gel Stain (Biotium, USA).

\section{DNA sequences and genetic analysis}

Three PCR-products with partial ORF2 were approximately 226 bp on $2 \%$ agarose gel and purified with viral gene extraction. DNA elution was amplified and submitted to Macrogen sequencing with primers PCV-ORF2-290F, PCV-ORF2-535R, and PCV-ORF2-516R. Moreover, 8 ORF2 sequences were selected from Universal Protein Resource (UniProt) and GenBank® (NIH genetic sequence database) based on PCV2 subtypes. Then 3 partial PCR sequences and thirteen referred sequences of ORF2 were aligned using Clustal Omega and MEGA7 [30,31].

\section{Statistical analysis}

Data were analyzed by PASW Statistics for Windows, version 18 (SPSS Inc., Chicago). Data from each group were compared using variance analysis (ANOVA) with Least Significant Difference (LSD) to compare the incidence between groups. Statistical significance was considered at $p$-value $\leq 0.05$.

\section{Results and discussion}

PCV2 and its subtypes became the endemic disease in the swine industry around the world, including Thailand. PCV2 causes 2 syndromes and shows age-dependent susceptibility, namely Postweaning Multisystemic Wasting Syndrome (PMWS) and Porcine Dermatitis and Nephropathy Syndrome (PDNS). Nowadays, the disease is named porcine circovirus disease (PCVD) or porcine circovirus associated disease (PCVAD) [32,33]. PCV2 comprises 4 subtypes based on ORF2 variation into PCV2a, PCV2b, PCV2c, and PCV2d, although the relation between clinicopathological features and PCV2 subtypes are still unclear. They should be better refined to study subtypes and clinical sign relation. Moreover, capsid protein plays an important role in the virus adhesion via heparan sulfate receptor on the target cell surface and antigenicity [34]. ORF2 was used in the viral detection for both parental and recombinant viruses by PCR detection and genetic determination [2,29].

One hundred blood samples from 14 farms in Thung Yai district, Nakhon Si Thammarat were collected and divided into 2 types based on pig production systems, farrowing-to-finishing, and nurseryto-finishing farms. $\beta$-actin gene was applied as an internal control to all DNA samples. Besides, the PCR product of ORF2 was approximately 226 bp in length on $2 \%$ agarose gel electrophoresis (Figure 2). Nine out of 100 samples were positive to PCV2. No gilt was PCV2 positive; however, approximately $90 \%$ of positive samples were finishing production, which composed of $67 \%$ of growing-to-finishing pigs, $22 \%$ of nursery-to-starter, and $11 \%$ of sows (Figure 3A). The Pearson correlation shows the low level of correlation between the group of samples (replacement gilts, sows, nursery to starters, and growing to finishing pigs) and positive detection within $\mathrm{Cr} \approx 0.245$. The growing to finishing pigs have the most positive result (67\% positive). Most growing to finishing pigs in smallholder farms in this study had no vaccination programs, which led to a high amount of positive results. For production type, the result showed slight correlation between breeding and finishing units $(\mathrm{Cr} \approx 0.212)$ (Figure 3B). The finishing farms rearing pigs from multiple sources are at greater risk than single-source pigs. This suggested that growing and finishing pigs should have a PCV2 vaccination. Moreover, the new groups of pigs should be vaccinated and evaluated for the immune status before entering the farm. However, it is not easy to do in smallholder farms. The most suitable methods are a pig-source selection from the negative farm and reliable sources $[23,25,35]$. 


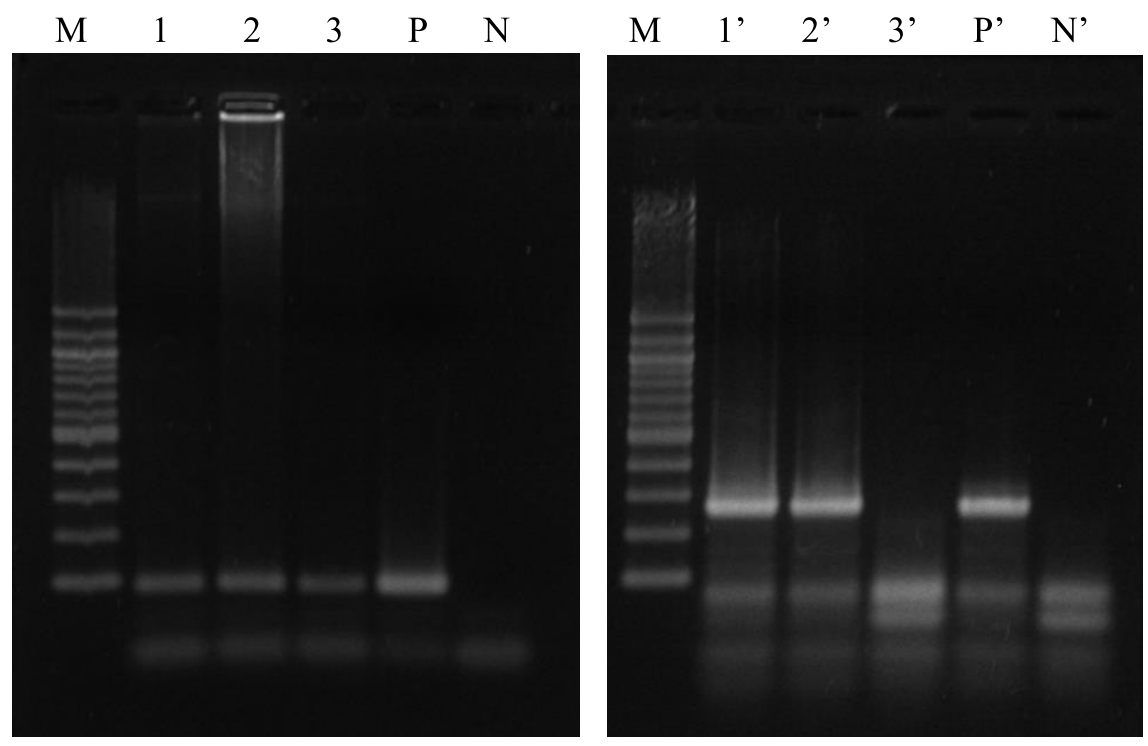

Figure 2 PCR products on $2 \%$ Agarose gel electrophoresis. M: 100 bp DNA marker; Lane 1-3: $\beta$-actin detection around $94 \mathrm{bp}$ in size; Lane 1'-3': PCV2 detection, and Lane P, N: positive and negative control for $\beta$-actin PCR, respectively; P', N': positive and negative control for ORF2 of PCV2 PCR.

PCV2 consists of 11 major genes but only 4 genes have been described, Replicase (ORF1), Capsid (ORF2), apoptosis associated PCV2 (ORF3), and caspase activity (ORF4) [36-40]. PCV2 has highly conserved nucleotides in ORF2. It has been classified on the basis of nucleotide sequencing evolution, which has 5 subtypes: PCV2a, PCV2b, PCV2c, PCV2d, and PCV2e. Three positive samples were carried out for DNA sequencing and compared to 13 published sequences on UniProt ${ }^{\circledR}$ and GenBank $\AA$ as nucleotide databases; PCV1: AY193712, AY184287; PCV2a: AF381177, AY699793; PCV2b: AY579893, DQ629117, KX831482; PCV2c: EU148504.1, EU148504; PCV2d: KX510085, MF169760; PCV3: KY418606, KX966193. The sequence alignment is shown in Figure S1. The 3 sequences were fully identical between sample group and over $95 \%$ between published PCV2b. This was followed by PCV2c, PCV2a, PCV1, PCV2d, and PCV3 (Table 1). This suggests that these positive samples were related to other provinces of Thailand (THA_07NP88:Nakhon Pathom, THA_10SB01:Saraburi) and several countries, AY556477 (China, 2004), EÜ302140 (Indonesia, 2008), JX099786 (Vietnam, 2008), JF690923 (Malaysia, 2011), and KY985387 (Africa, 2017) [2,35,41,42]. 
(A)

$$
\text { Percentage of Positve Results }
$$

$(\mathrm{Cr} \approx 0.245)$

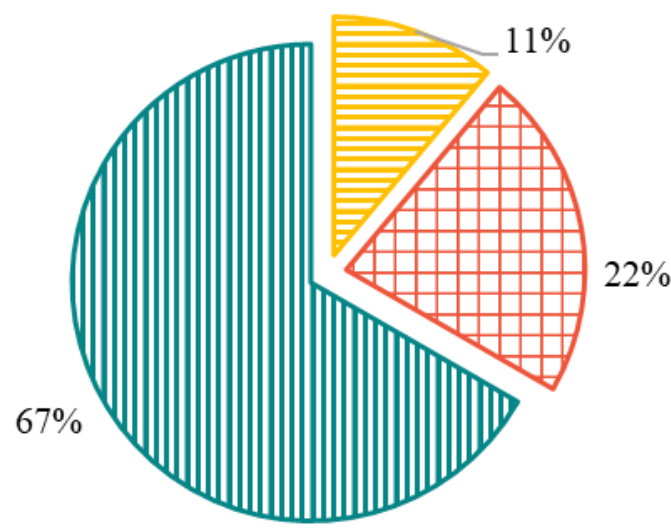

• Gilt $\boxminus$ Sow $\square$ Nursery mGrower
(B)

Percentage of Positve in Type of Farm

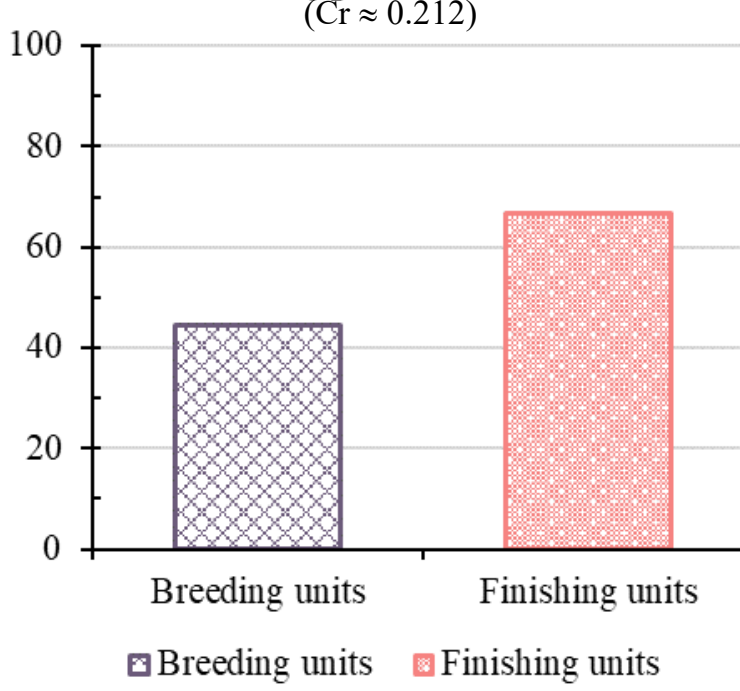

Figure 3 (A) The circular schematic diagram demonstrated the percentage of positive samples from blood samples $(\mathrm{N}=100)$. The growing to finishing group was labeled with green lines; nursery to starter (bright red), and sow (yellow). (B) The histogram showed the percentage of positive within production units. Both breeding units and finishing units had mild correlations value $(\mathrm{Cr} \approx 0.212)$ with a positive result (PCR detection) significantly at $\mathrm{p}<0.05$ using a Pearson correlation.

In addition, good management procedures of farms such as biosecurity systems and husbandry practices are the most important means. This study found that most of the finishing farms cannot perform the confined and acclimatized procedure, all in/all-out system, and effectively vaccination programs. This leads to retaining the PCV2 circulation in the farm environment and the effect of age dependent infection. The disinfectant selection is required to inactivate the viral load in the farm due to great disinfectantresistance. For instance, potassium peroxymonosulfate (KHSO5), sodium hypochlorite $(\mathrm{NaOCl})$, sodium hydroxide $(\mathrm{NaOH})$, quaternary ammonium, except the group of ethanol, chlorhexidine, and aldehydes are less active for PCV $[43,44]$. On the other hand, the breeding unit, both gilts, and sows have obtained intermittent vaccination programs due to the low level of PCV2 infection (11\% positive). The groups of nursery-to-starter and growing-to-finishing pigs are approximately 22 and $67 \%$ positive, respectively. This conforms to the non-vaccination in nursery-to-finishing group. This suggests that both groups should be regularly vaccinated and monitored for viral detection sporadically. Furthermore, smallholder farmers should be educated on the effective biosecurity system and productive husbandry practices to improve pig production and reduce the risk of PCV2 infection.

\section{Conclusions}

This study examined the prevalence of PCV2 in pig smallholder farms in Thung Yai district, Nakhon Si Thammarat, Thailand. Findings suggest that the PCV2 is classified into PCV2 subtype B, similar to previous reports in Thailand and neighboring countries. Nevertheless, the complete PCV2 genome analysis and comparison of large holder farms (main pig source) and smallholder farms should be confirmed to practice the specific southern region's strategic control. 
http://wjst.wu.ac.th

\section{Acknowledgements}

We would like to express our grateful appreciation to Jarupong Musikapong, Anonsak Kongsuk, Sirisa Nookeaw, $6^{\text {th }}$ year-student Faculty of Veterinary Science, Rajamangala University of Technology Srivijaya, for assisting in the field survey. The Individual Research Grant (IRG) is provided by Grant: DR2561-26012010, Faculty of Veterinary Science, Rajamangala University of Technology Srivijaya. We would like to extend our sincere thanks to $24 \mathrm{~h}$ activity on the Garden of Submission theme, Walailak University, Thailand, who encouraged us to do this manuscript.

\section{References}

[1] P Nawagitgul, PA Harms, I Morozov, BJ Thacker, SD Sorden, C Lekcharoensuk and PS Paul. Modified indirect porcine circovirus (PCV) type 2-based and recombinant capsid protein (ORF2)based enzyme-linked immunosorbent assays for detection of antibodies to PCV. Clin. Diagn. Lab. Immunol. 2002; 9, 33-40.

[2] N Thangthamniyom, $\mathrm{P}$ Sangthong, $\mathrm{P}$ Poolperm, $\mathrm{N}$ Thanantong, A Boonsoongnern, $\mathrm{P}$ Hansoongnern, P Semkum, N Petcharat and P Lekcharoensuk. Genetic diversity of porcine circovirus type 2 (PCV2) in Thailand during 2009-2015. Vet. Microbiol. 2017; 208, 239-46.

[3] R Tantilertcharoen, W Kiatipattanasakul and R Thanawongnuwech. Report of circovirus infection in pigs in Thailand. Thai J. Vet. Med. 1999; 29, 73-83.

[4] L Zhang, Y Luo, L Liang, J Li and S Cui. Phylogenetic analysis of porcine circovirus type3 and porcine circovirus type 2 in China detected by duplex nanoparticle-assisted PCR. Infect. Genet. Evol. 2018; 60, 1-6.

[5] KO Afolabi, BC Iweriebor, AI Okoh and LC Obi. Global status of Porcine circovirus type 2 and its associated diseases in sub-Saharan Africa. Adv. Virol. 2017; 2017, 6807964.

[6] GM Allan, F McNeilly, I McNair, MD Curran, I Walker, J Ellis, C Konoby, S Kennedy and B Meehan. Absence of evidence for porcine circovirus type 2 in cattle and humans, and lack of seroconversion or lesions in experimentally infected sheep. Arch. Virol. 2000; 145, 853-7.

[7] BM Meehan, F McNeilly, D Todd, S Kennedy, VA Jewhurst, JA Ellis, LE Hassard, EG Clark, DM Haines and GM Allan. Characterization of novel circovirus DNAs associated with wasting syndromes in pigs. J. Gen. Virol. 1998; 79, 2171-9.

[8] R Palinski, P Piñeyro, P Shang, F Yuan, R Guo, Y Fang, E Byers and BM Hause. A novel porcine circovirus distantly related to known circoviruses is associated with porcine dermatitis and nephropathy syndrome and reproductive failure. J. Virol. 2017; 91, e01879-16.

[9] L Cao, W Sun, H Lu, M Tian, C Xie, G Zhao, J Han, W Wang, M Zheng, R Du, N Jin and A Qian. Genetic variation analysis of PCV1 strains isolated from Guangxi Province of China in 2015. BMC Vet. Res. 2018; 14, 43.

[10] I Tischer, H Gelderblom, W Vettermann and MA Koch. A very small porcine virus with circular single-stranded DNA. Nature 1982; 295, 64-6.

[11] I Tischer, R Rasch and G Tochtermann. Characterization of papovavirus-and picornavirus-like particles in permanent pig kidney cell lines. Zentralbl. Bakteriol. Orig. A 1974; 226, 153-67.

[12] B Jacobsen, L Krueger, F Seeliger, M Bruegmann, J Segalés and W Baumgaertner. Retrospective study on the occurrence of porcine circovirus 2 infection and associated entities in Northern Germany. Vet. Microbiol. 2009; 138, 27-33.

[13] T Kwon, SJ Yoo, CK Park and YS Lyoo. Prevalence of novel porcine circovirus 3 in Korean pig populations. Vet. Microbiol. 2017; 207, 178-80.

[14] C Chae. Postweaning multisystemic wasting syndrome: a review of aetiology, diagnosis and pathology. Vet. J. 2004; 168, 41-9.

[15] J Prpić, T Keros, T Bedeković, D Brnić, Ž Cvetnić, B Roić and L Jemeršić. Phylogenetic comparison of porcine circovirus type 2 (PCV2) and porcine reproductive respiratory syndrome virus (PRRSV) strains detected in domestic pigs until 2008 and in 2012 in Croatia. Ir. Vet. J. 2014; 67, 9. 
http://wjst.wu.ac.th

[16] P Alarcon, J Rushton and B Wieland. Cost of post-weaning multi-systemic wasting syndrome and porcine circovirus type-2 subclinical infection in England: An economic disease model. Prev. Vet. Med. 2013; 110, 88-102.

[17] N Rose, T Opriessnig, B Grasland and A Jestin. Epidemiology and transmission of porcine circovirus type 2 (PCV2). Virus Res. 2012; 164, 78-89.

[18] KA Woodbine, MJ Turner, GF Medley, PD Scott, AJ Easton, J Slevin, JC Brown, L Francis and LE Green. A cohort study of post-weaning multisystemic wasting syndrome and PCV2 in 178 pigs from birth to 14 weeks on a single farm in England. Prev. Vet. Med. 2010; 97, 100-6.

[19] SL Zhai, DS He, WB Qi, SN Chen, SF Deng, J Hu, XP Li, L Li, RA Chen, ML Luo and WK Wei. Complete genome characterization and phylogenetic analysis of three distinct buffalo-origin PCV2 isolates from China. Infec. Genet. Evol. 2014; 28, 278-82.

[20] J Segalés and M Domingo. Postweaning mulstisystemic wasting syndrome (PMWS) in pigs: A review. Vet. Quart. 2002; 24, 109-24.

[21] E Wilfred, F Mutebi, FN Mwiine, OA James and O Lonzy. Porcine Circovirus type 2: Systemic disease on pig farms and associated knowledge of key players in the pig industry in Central Uganda. Int. J. Vet. Sci. Med. 2018; 6, 178-85.

[22] R Anoopraj, JK John, M Sethi, R Somvanshi and G Saikumar. Isolation and identification of porcine circovirus 2 from cases of respiratory disease and postweaning multisystemic wasting syndrome in pigs. Adv. Anim. Vet. Sci. 2014; 2, 365-8.

[23] R Anoopraj, TK Rajkhowa, S Cherian, RS Arya, N Tomar, A Gupta, PK Ray, R Somvanshi and G Saikumar. Genetic characterisation and phylogenetic analysis of PCV2 isolates from India: Indications for emergence of natural inter-genotypic recombinants. Infect. Genet. Evol. 2015; 31, 25-32.

[24] C Chae. Porcine respiratory disease complex: Interaction of vaccination and porcine circovirus type 2, porcine reproductive and respiratory syndrome virus, and Mycoplasma hyopneumoniae. Vet. J. $2016 ; 212,1-6$.

[25] P Mukherjee, A Karam, L Barkalita, P Borah, AK Chakraborty, S Das, K Puro, R Sanjukta, S Ghatak, I Shakuntala, RG Laha, A Sen and I Sharma. Porcine circovirus 2 in the North Eastern region of India: Disease prevalence and genetic variation among the isolates from areas of intensive pig rearing. Acta Trop. 2018; 182, 166-72.

[26] CMT Dvorak, Y Yang, C Haley, N Sharma and MP Murtaugh. National reduction in porcine circovirus type 2 prevalence following introduction of vaccination. Vet. Microbiol. 2016; 189, 8690.

[27] M Kixmöller, M Ritzmann, M Eddicks, A Saalmüller, K Elbers and V Fachinger. Reduction of PMWS-associated clinical signs and co-infections by vaccination against PCV2. Vaccine 2008; 26, 3443-51.

[28] H Wang, J Gu, G Xing, X Qiu, S An, Y Wang, C Zhang, C Liu, W Gong, C Tu, S Su and J Zhou. Genetic diversity of porcine circovirus type 2 in China between 1999-2017. Transbound. Emerg. Dis. 2019; 66, 599-605.

[29] R Larochelle, A Bielanski, P Müller and R Magar. PCR detection and evidence of shedding of porcine circovirus type 2 in boar semen. J. Clin. Microbiol. 2000; 38, 4629-32.

[30] S Kumar, G Stecher and K Tamura. MEGA7: Molecular evolutionary genetics analysis version 7.0 for bigger datasets. Mol. Biol. Evol. 2016; 33, 1870-4.

[31] F Sievers, A Wilm, D Dineen, TJ Gibson, K Karplus, W Li, R Lopez, H McWilliam, M Remmert, J Söding, JD Thompson and DG Higgins. Fast, scalable generation of high-quality protein multiple sequence alignments using Clustal Omega. Mol. Syst. Biol. 2011; 7, 539.

[32] G Allan, S Krakowka and J Ellis. PCV2; ticking time bomb? Pig Progress 2002; 18, 14-5.

[33] T Opriessnig, XJ Meng and PG Halbur. Porcine circovirus type 2-associated disease: Update on current terminology, clinical manifestations, pathogenesis, diagnosis, and intervention strategies. $J$. Vet. Diagn. Invest. 2007; 19, 591-615. 
http://wjst.wu.ac.th

[34] G Misinzo, PL Delputte, P Meerts, DJ Lefebvre and HJ Nauwynck. Porcine circovirus 2 uses heparan sulfate and chondroitin sulfate B glycosaminoglycans as receptors for its attachment to host cells. J. Virol. 2006; 80, 3487-94.

[35] L Cai, J Ni, Y Xia, Z Zi, K Ning, P Qiu, X Li, B Wang, Q Liu, D Hu, X Yu, Z Zhou, X Zhai, X Han and $\mathrm{K}$ Tian. Identification of an emerging recombinant cluster in porcine circovirus type 2. Virus Res. 2012; 165, 95-102.

[36] AL Hamel, LL Lin and GPS Nayar. Nucleotide sequence of porcine circovirus associated with postweaning multisystemic wasting syndrome in pigs. J. Virol. 1998; 72, 5262-7.

[37] AK Cheung. Transcriptional analysis of porcine circovirus type 2. Virology 2003; 305, 168-80.

[38] P Nawagitgul, I Morozov, SR Bolin, PA Harms, SD Sorden and PS Paul. Open reading frame 2 of porcine circovirus type 2 encodes a major capsid protein. J. Gen. Virol. 2000; 81, 2281-7.

[39] J Liu, I Chen and J Kwang. Characterization of a previously unidentified viral protein in porcine circovirus type 2-infected cells and its role in virus-induced apoptosis. J. Virol. 2005; 79, 8262-74.

[40] J He, J Cao, N Zhou, Y Jin, J Wu and J Zhou. Identification and functional analysis of the novel ORF4 protein encoded by porcine circovirus type 2. J. Virol. 2013; 87, 1420-9.

[41] S Jittimanee, SNN Ayudhya, R Kedkovid, K Teankum and R Thanawongnuwech. Genetic characterization and phylogenetic analysis of porcine circovirus type 2 in Thai pigs with porcine circovirus associated diseases (PCVAD) during 2007-2010. Thai J. Vet. Med. 2011; 41, 163-70.

[42] TML Huynh, BH Nguyen, VG Nguyen, HA Dang, TN Mai, THG Tran, MH Ngo, VT Le, TN Vu, TKC Ta, VH Vo, HK Kim and BK Park. Phylogenetic and phylogeographic analyses of porcine circovirus type 2 among pig farms in Vietnam. Transbound. Emerg. Dis. 2014; 61, e25-e34.

[43] RL Royer, P Nawagitgul, PG Halbur and PS Paul. Susceptibility of porcine circovirus type 2 to commercial and laboratory disinfectants. J. Swine Health Prod. 2001; 9, 281-4.

[44] R Isomura, M Matsuda and K Sugiura. An epidemiological analysis of the level of biosecurity and animal welfare on pig farms in Japan and their effect on the use of veterinary antimicrobials. J. Vet. Med. Sci. 2018; 80, 1853-60. 


\section{Supplementary document}

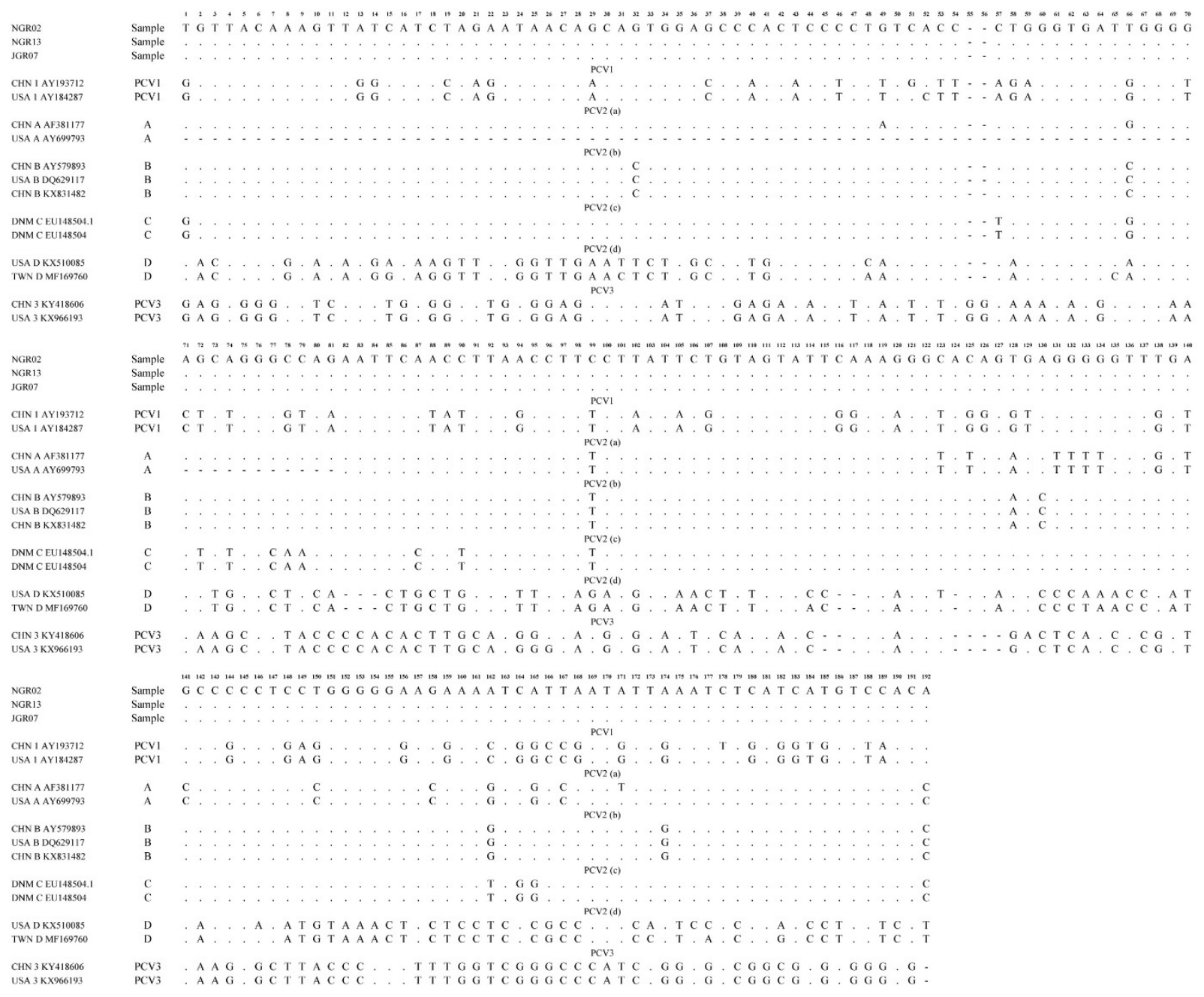

Figure S1 Nucleotides sequence alignment of partial ORF2 of 3 local sequences and 13 referred sequences from GenBank ${ }^{\circledR}$ (NIH genetic sequence database) of PCV2. The symbol (.) represents the fully conserved residue and (-) point to the gap between nucleotides. 